\title{
Automedicação entre docentes de nível superior
}

\section{Self-medication among university lecturers}

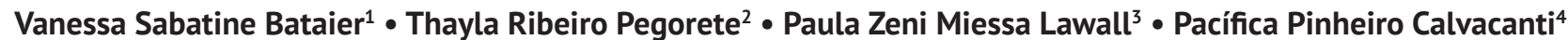

\begin{abstract}
RESUMO
Objetiva-se identificar o perfil de docentes de nível superior que efetuam a prática da automedicação. Trata-se de um estudo de prevalência. Foram entrevistados 82 professores, de ambos os sexos, no período novembro de 2013 a março de 2014. As entrevistas foram submetidas à análise estatística descritiva e distribuição de frequências, e à técnica de análise temática, para os dados quantitativos e qualitativos, respectivamente. A automedicação é praticada entre os professores do sexo feminino (51\%) e graduados sem nenhum tipo de especialização (42,6\%). A principal classe de medicamentos utilizada nesta prática, foi a dos analgésico-antitérmicos (95\%) e a patologia ou sintoma que motivou a automedicação, foi a dor de cabeça (80,5\%). Estes medicamentos foram autoindicados em $60 \%$ e motivados por conhecimentos adquiridos ao longo da vida (33\%). Dos principais desfechos da automedicação, $78 \%$ obtiveram remissão do sintoma que o levou à prática. Concluí-se que a comunidade docente sendo formadora de opiniões, uma maneira de diminuir os índices de automedicação seria conscientizá-la dos perigos da mesma, para que este saber seja replicado.
\end{abstract}

Palavras-chave: Automedicação; Professores; Educação em Saúde.

\begin{abstract}
The aim is to identify the profile of university lecturers who practice self-medication. This is a prevalence study. They interviewed 82 teachers, of both genders, in the period from November 2013 to March 2014. These interviews were submitted to descriptive statistics and frequency distribution, and thematic analysis for quantitative and qualitative data, respectively. Self-medication is practiced among female teachers (51\%) and graduates without any specialization (42.6\%). The main class of drugs used in this practice, it was the analgesic-antipyretics (95\%) and the condition or symptom that led to self-medication was headache (80.5\%). These drugs comprehend $60 \%$ of self-medication and motivated by knowledge acquired throughout life (33\%). Of the main outcomes of selfmedication, $78 \%$ achieved remission of symptoms that led to the practice. It concludes that since the teaching community is opinion leader, one way to reduce self-medication rates would educate her from the dangers of it, to know that this is replicated.
\end{abstract}

Keywords: Self-medication; Teachers; Health Education.

${ }^{1}$ Enfermeira no Hospital Regional Albert Sabin, Alta Floresta, MT, Brasil. E-mail: vanessa.sabatine@hotmail.com

${ }^{2}$ Aluna do Curso de Enfermagem da Universidade Federal de Mato Grosso. E-mail: thaylapegorete@hotmail.com

${ }^{3}$ Médica especialista em Medicina de Família e Comunidade e em Clínica Médica. Professora Auxiliar do Curso de Medicina na Universidade Federal de Mato Grosso. Coordenadora da Residência Médica da Universidade Federal de Mato Grosso. Médica da Estratégia de Saúde da Família da Prefeitura Municipal de Sinop-MT. Email: haipipous@yahoo.com.br.

${ }^{4}$ Enfermeira. Doutora em Farmacologia pela Universidade Federal do Ceará. Líder do Grupo de Estudos e Pesquisa em Saúde Interdisciplinar. Professora Adjunta do Curso de Graduação em Enfermagem da Universidade Federal de Mato Grosso. E-mail: pacificapinheiro@gmail.com

Recorte da Monografia de Conclusão de Curso intitulada "Automedicação na comunidade docente da Universidade Federal do Mato Grosso do Campus Universitário de Sinop" de autoria de Vanessa Sabatine Bataier (Monografia de Conclusão de Curso). Curso de Graduação em Enfermagem da Universidade Federal do Mato Grosso/UFMT. Sinop, MT. Data da defesa 15/08/2014.

Os autores declaram não haver conflitos de interesse nem fontes de financiamento. 


\section{INTRODUÇÃO}

A automedicação é o ato de escolher uma medicação e ministrá-la a si mesmo, sem prescrição médica, incluindo o fornecimento, a recomendação ou orientação do uso de medicamentos por pessoas não habilitadas, como vizinhos, amigos, familiares, balconistas da farmácia, influência de propagandas desenfreadas e massivas, sendo uma prática bastante difundida, não apenas no Brasil, mas também em outros países ${ }^{1-2}$.

Entre outros problemas, a automedicação pode mascarar diagnósticos na fase inicial da doença, tornandose uma medida auto-protetiva não efetiva, pois pode diminuir sinais e sintomas, em um primeiro momento, nem sempre tratando adequadamente o problema em questão, e ainda permitir que os mesmos ressurjam de forma potencializada, o conhecido "efeito rebote"

É de suma importância existir atenção especial, principalmente sobre o uso de substâncias psicoativas, pois o indivíduo que se automedica e que faz uso indiscriminado, pode perder o controle sobre a droga, incorrendo dependência física, psíquica e farmacológica³.

A desinformação entre os que utilizam esta abordagem é outro ponto crítico, pois ocasiona escolhas de baixa qualidade ou indicações equivocadas, como o uso de um antibiótico para infecções virais, o uso desnecessário de fármacos para doenças autolimitadas e a prática de suplementação para supostas carências nutricionais.

Porém, até mesmo os profissionais da saúde que têm conhecimento sobre os riscos da automedicação, a praticam, visto que se sentem seguros e confiantes quanto aos seus conhecimentos adquiridos durante a graduação e prática profissional, e por se considerarem mais suscetíveis à manifestação ou instalação de doenças físicas ou psíquicas, em virtude da relação da exposição à doentes e aos desgastes vinculados ao próprio processo de trabalho. 0 fato dos profissionais se automedicarem, preocupa, inclusive, devido ao peso social de sua responsabilidade, e o estigma de servir de exemplo a todos, principalmente seus pacientes ${ }^{3}$.

Alguns dos motivos que levam à automedicação são a dificuldade, a demora e o custo para se conseguir uma opinião médica, a limitação do poder prescritivo restrito a poucos profissionais de saúde, o desespero e a angústia desencadeados por sintomas ou pela possibilidade de se ter ou adquirir uma doença; e por fim, encurtar os caminhos para o alívio².

É importante que haja conscientização quanto ao uso racional dos medicamentos, principalmente entre aqueles da área da saúde, já que repassarão informações e deverão construir e ampliar o vínculo de confiança e adesão dos que os procuram para opinião clínica e sugestão de conduta ${ }^{5}$.

Aos que não são da área da saúde, deve-se ter visão e abordagem com atenção redobrada, pois as mesmas, não só de forma indireta, induzem outras pessoas a esta prática tão sedimentada.
Faz-se mister criar estratégias específicas nos mais diversos setores, dando importância especial aos profissionais da área da saúde, e não obstante, conscientizar e informar a população dos perigos da automedicação, apresentando as vantagens de uma prescrição responsável.

0 estudo tem como objetivo identificar o perfil de docentes de nível superior que efetuam a prática da automedicação.

\section{MÉTODO}

Trata-se de um estudo de prevalência. Tais estudos são recomendados quando se deseja estimar a frequência com que um determinado evento de saúde se manifesta em uma população específica, além dos fatores associados com o mesmo. Também consiste em uma ferramenta de grande utilidade para a descrição de características da população, para a identificação de grupos de risco e para a ação e planejamento em saúde ${ }^{6}$.

Empregou-se a amostragem por conveniência, consistindo em utilizar um grupo de indivíduos que esteja disponível ou um grupo de voluntários, ou seja, os indivíduos da pesquisa são selecionados porque eles estão disponíveis, não porque eles foram selecionados por meio de um critério estatístico ${ }^{7}$.

A pesquisa foi realizada com 82 professores dos três institutos: Instituto de Ciências da Saúde (ICS), Instituto de Ciências Agrárias e Ambientais (ICAA) e Instituto de Ciências Naturais, Humanas e Sociais (ICNHS), da Universidade Federal de Mato Grosso, do Campus Universitário de Sinop/MT. Este estudo envolveu indivíduos de ambos os sexos e que se dispuseram a participar voluntariamente da pesquisa, após leitura e assinatura do Termo de Consentimento Livre e Esclarecido.

Todos os participantes tiveram suas identidades preservadas. Para garantir o anonimato dos professores, foram atribuídos codinomes fictícios de flores, escolhidos aleatoriamente. Foram excluídos da pesquisa indivíduos que não concordaram em participar desse estudo, pessoas que não fazem parte da comunidade acadêmica da Universidade Federal de Mato Grosso do Campus Sinop/MT e não docentes.

Os dados foram coletados, no período de novembro de 2013 a março de 2014, através de um questionário semiestruturado com perguntas abertas e fechadas previamente estabelecidas.

Os dados quantitativos foram analisados através da estatística descritiva e distribuição de frequências e foram apresentados na forma de tabelas. Para a análise dos dados foi utilizado o software Excel ${ }^{\circledR} 2007$.

Os dados qualitativos foram analisados após as entrevistas, por meio da técnica de análise temática, que consiste em explorar e concretizar os conceitos ou ideias constituintes da comunicação, a fim de realizar a interpretação para o objetivo visado 8 . 
A pesquisa foi conduzida de acordo com a Resolução 466/2012 do Conselho Nacional de Saúde/Ministério da Saúde e o projeto foi aprovado pelo Comitê de Ética em Pesquisa do Hospital Universitário Júlio Muller, sob o protocolo número 218.976.

\section{RESULTADOS}

\section{Perfil socioeconômico dos professores}

As características sociodemográficas dos professores de nível superior que constituíram a amostra podem ser visualizadas na tabela 1.

Tabela 1- Características sociodemográficas dos professores do Campus Universitário de Sinop/MT, Brasil, 2013-2014

\begin{tabular}{|c|c|c|}
\hline Variáveis & $\mathbf{N}$ & $\%$ \\
\hline \multicolumn{3}{|l|}{ Faixa etária (n:82) } \\
\hline < ou igual a 30 & 13 & 16 \\
\hline 31 a 60 & 69 & 84 \\
\hline \multicolumn{3}{|l|}{ Sexo (n: 82) } \\
\hline Feminino & 42 & 51 \\
\hline Masculino & 40 & 49 \\
\hline \multicolumn{3}{|l|}{ Estado Civil (n: 82) } \\
\hline Casado (a) & 54 & 65,15 \\
\hline Solteiro (a) & 28 & 34,15 \\
\hline \multicolumn{3}{|l|}{ Naturalidade (n: 82) } \\
\hline Mato Grosso & 11 & 13,5 \\
\hline Outro Estado & 70 & 85,4 \\
\hline Outro País & 1 & 1,1 \\
\hline \multicolumn{3}{|l|}{ Grau de Escolaridade (n: 82) } \\
\hline Somente Graduado & 35 & 42,6 \\
\hline Graduado c/ Especialização & 10 & 12,4 \\
\hline Mestrado & 5 & 6 \\
\hline Doutorado & 32 & 39 \\
\hline \multicolumn{3}{|c|}{ Pessoas com quem residem ( $\mathrm{n}: 82$ ) } \\
\hline Sozinho (a) & 16 & 19,5 \\
\hline Amigo (a) & 1 & 1,2 \\
\hline Companheiro (a) & 24 & 29,2 \\
\hline Parente (mãe, irmão, tios...) & 3 & 3,6 \\
\hline Companheiro (a) e filhos & 30 & 36,5 \\
\hline Não Responderam & 8 & 10 \\
\hline
\end{tabular}

Fonte: dados da pesquisa.

Com relação à faixa etária, $16 \%$ dos pesquisados tinham idade menor ou igual à 30 anos; em $84 \%$, a idade variou entre 31 a 60 anos.

Quanto ao sexo, observamos maior participação feminina, com $51 \%$ dos pesquisados e $49 \%$ do sexo masculino. A maioria dos participantes são casados (65,1\%), seguido de $34,1 \%$ de solteiros.
Dos pesquisados, $85,4 \%$ são naturais de outro estado, $13,5 \%$ são nascidos no Mato Grosso e $1,1 \%$ outro país (Peru).

Em relação à escolaridade, as variáveis foram de acordo com os requisitos para contratação da instituição, logo, todos os voluntários são graduados, sendo que $42,6 \%$ tinham somente graduação, $12,4 \%$ possuíam algum tipo de especialização, $6 \%$ eram mestres e $39 \%$ eram doutores.

Quando indagados sobre as pessoas com quem os docentes residem; apenas 19,5\% dos professores moram sozinhos, $29,2 \%$, residem com o companheiro, $36,5 \%$ residem com companheiro e filhos, 3,6\% moram com parente, e somente $1,2 \%$ moram com um parente ou com um (a) amigo (a).

\section{Classes Farmacológicas dos medicamentos mais utilizados e patologias ou sintomas que motivaram a prática da automedicação}

Na tabela 2 é possível mensurar a alta taxa de utilização dos Analgésico-Antitérmicos entre os pesquisados (95\%), seguidos dos antiinflamatórios não esteroidais (AINES) (74\%).

Tabela 2 - Principais medicamentos utilizados e patologias ou sintomas relatados pelos professores de nível superior do Campus Universitário de Sinop/MT, Brasil, 2013-2014

\begin{tabular}{l|c|c}
\hline \multicolumn{1}{c|}{ Variáveis } & N & $\%$ \\
\hline Analgésicos/Antitérmicos (n: 82) & 78 & 95 \\
\hline Antiinflamatórios (n: 82) & 61 & 74 \\
\hline Antitussígeno (n:82) & 60 & 73 \\
\hline Antibióticos (n: 82) & 22 & 27 \\
\hline Antialérgicos/Anti-histamínicos (n:82) & 31 & 38 \\
\hline Antigripais (n: 82) & 61 & 74 \\
\hline Sedativos & 3 & 4 \\
\hline Dor de cabeça (n: 82) & 66 & 80,5 \\
\hline Dor muscular (n: 82) & 40 & 49 \\
\hline Febre (n: 82) & 45 & 55 \\
\hline Resfriado/Gripe (n: 82) & 58 & 71 \\
\hline Infecções/inflamações de garganta (n: 82) & 34 & 41,5 \\
\hline Sinusite (n: 82) & 18 & 22 \\
\hline Alergias (n: 82) & 24 & 29 \\
\hline Ansiedades (n: 82) & 11 & 13,4 \\
\hline Outros: (n: 82) & 4 & 4,8 \\
\hline
\end{tabular}

Fonte: dados da pesquisa.

O antitussígeno e os medicamentos sintomáticos utilizados para resfriado/gripe obtiveram destaque, representando $73 \%$ das escolhas.

Os anti-histamínicos, também conhecidos como antialérgicos, tiveram 38\% das indicações, enquanto os antibióticos apareceram com $27 \%$ das referidas automedicações. 
As drogas psicoativas, como os fármacos ansiolíticos, foram utilizados por $4 \%$ dos pesquisados.

Outros medicamentos não incluídos no questionário correspondem a $10 \%$, não sendo especificados quais seriam esses.

Apesar dos AINES terem sido a classe farmacológica preferencial do corpo docente, é importante chamar atenção para os antibióticos e sedativos que são medicamentos para os quais existe prerrogativa legal da necessidade de prescrição médica e retenção de receita para obtenção dos mesmos. Entretanto, alguns docentes tiveram acesso a esses medicamentos, mesmo sem a prescrição.

Das patologias elencadas, a dor de cabeça representou $80 \%$ de escolha, e os resfriados/gripe, somam $71 \%$. Quanto à febre, referida por $55 \%$ dos pesquisados, ficou em terceiro lugar na seleção dos docentes.

A dor muscular foi a causa descrita por quase a metade do corpo docente, tendo sido mencionada por $49 \%$ das escolhas.

Contrário a dor muscular, as infecções ou inflamações vão além de tratamentos apenas paliativos. As infecções ou inflamações de garganta somam 41,5\% das indicações de causas para a automedicação. Muitos não sabem a diferença entre infecção e inflamação e acabam escolhendo o tratamento errôneo para o seu problema. 0 erro de escolha do medicamento correto pode ser observado através do depoimento de Jasmim:

“Tenho enxaqueca e às vezes tomo remédio para acalmar a dor. Quando tenho inflamação bacteriana, tomo antiinflamatório, mas não gosto de tomar nenhum tipo de remédio, só o tomo quando não suporto a dor (Jasmim)".

As alergias (29\%), sinusite (22\%), ansiedade (13,4\%) foram as patologias menos citadas pelos professores.

\section{Características motivacionais não patológicas ou sintomáticas que incentivaram a prática da automedicação}

Evidencia-se que 60\% (Tabela 3) optou por se automedicar sem interferência externa, ou seja, por si próprio. Os familiares ou amigos foram responsáveis por $23 \%$ das indicações.

A busca pelo farmacêutico entre os pesquisados não foi tão expressiva, apenas $15 \%$ dos professores escolheram por se consultar com o farmacêutico ao comprar um medicamento sem receita.

Outra fonte de uso inadequado dos medicamentos são as informações na internet e propagandas nos meios de comunicações, especialmente na televisão, que obteve $2 \%$ da escolha dos pesquisados.

Um dado que chamou atenção na pesquisa é o fato dos participantes terem marcado mais de uma alternativa quando indagados sobre a indicação da medicação, sendo que $33,3 \%$ dos professores afirmaram ter tido mais de um
Tabela 3 - Características motivacionais para adesão à prática da automedicação dos professores do Campus Universitário de Sinop/ MT, Brasil, 2013-2014

\begin{tabular}{|c|c|c|}
\hline Variáveis & $\mathbf{N}$ & $\%$ \\
\hline \multicolumn{3}{|l|}{ Fonte de indicação da medicação ( $n: 57$ ) } \\
\hline Farmacêutico & 9 & 15 \\
\hline Eu mesmo & 34 & 60 \\
\hline Familiares/amigos & 13 & 23 \\
\hline $\begin{array}{l}\text { Buscou informações na Internet e } \\
\text { propaganda na televisão }\end{array}$ & 1 & 2 \\
\hline Mais de uma das alternativas & 19 & 33.3 \\
\hline Não responderam (n: 82) & 25 & 30,5 \\
\hline \multicolumn{3}{|l|}{ Critérios (n: 81) } \\
\hline Eficácia em usos anteriores & 17 & 21 \\
\hline Conhecimentos adquiridos & 26 & 33 \\
\hline Eficácia na indicação de terceiros & 13 & 16 \\
\hline $\begin{array}{l}\text { Eficácia em usos anteriores (receitas } \\
\text { antigas) }\end{array}$ & 15 & 18 \\
\hline Outros & 10 & 12 \\
\hline
\end{tabular}

Ao se automedicar:

\begin{tabular}{l|c|c}
\hline Segue as instruções da bula (n: 82) & 77 & 94 \\
\hline $\begin{array}{l}\text { Aconselha-se com o farmacêutico ou } \\
\text { balconista (n: 82) }\end{array}$ & 62 & 76 \\
\hline $\begin{array}{l}\text { Recebe conselhos não solicitados (na } \\
\text { farmácia) (n: 82) }\end{array}$ & 59 & 72 \\
\hline $\begin{array}{l}\text { Baseia-se em receitas médicas antigas } \\
\text { (n: } 82 \text { ) }\end{array}$ & 52 & 63,4 \\
\hline
\end{tabular}

Dentre os que se basearam em receitas antigas, essas receitas eram: ( $n: 52)$

\begin{tabular}{l|c|c}
\hline Suas & 46 & 88 \\
\hline De outras pessoas & 1 & 2 \\
\hline Suas e outras pessoas & 5 & 10 \\
\hline
\end{tabular}

Fonte: dados da pesquisa.

tipo de fonte de indicação para a automedicação. Apesar de não ter sido muito expressivo, observa-se a necessidade de uma promoção de uso de medicamentos de forma responsável na universidade, independente da formação e instituto a qual o indivíduo pertence.

Quanto aos critérios para adesão à prática da automedicação, $33 \%$ optaram pelos conhecimentos adquiridos, sejam eles durante a graduação, de acordo com a formação, ou por informações obtidas ao longo da vida.

Como critério da escolha do medicamento, a eficácia no uso anterior sem consultar a receita médica foi indicado por $21 \%$ dos entrevistados, seguido de eficácia nos usos anteriores de medicamentos, porém com receita médica (18\%) e eficácia na indicação para terceiros, referido por $16 \%$ do grupo, ou seja, um terceiro usou o medicamento com ou sem receita, obteve resultado positivo do medicamento e, por sua vez, indicou para o entrevistado, havendo assim, uma nova automedicação. 
Pode-se perceber que o resultado positivo prévio da prática da automedicação, leva à repetição da mesma. Em primeiro lugar, ao se automedicarem, $94 \%$ dos professores seguem as instruções da bula.

Em segunda e terceira posição, na escolha dos professores, para essa conduta medicamentosa, $76 \%$ procuram aconselhar-se com farmacêuticos e balconistas e 72 \% recebem conselhos mesmo que não solicitados na farmácia.

Apesar dos pesquisados que se baseiam em receitas médicas antigas para a prática da automedicação, ter sido dentre as variáveis, a menos citada $(63,4 \%)$, é um resultado bastante significativo e, dentre eles, $88 \%$ usam as próprias receitas antigas, $10 \%$ utilizam as próprias receitas e de terceiros e $2 \%$ utilizam prescrições de outros.

Observa-se vários critérios escolhidos pelos docentes, entre eles os conhecimentos adquiridos ao longo da vida. Resta saber se estes conhecimentos são realmente de fontes fidedignas, pois como visualizado, muitos optaram aconselhar-se com amigos e parentes, estas pessoas que são consideradas de confiança, indicam essas medicações por experiências vividas e não por conhecimentos literários.

Vale lembrar que os professores são pessoas admiradas por seus alunos e por isso podem influenciar diretamente ou indiretamente nas decisões de seus alunos, independente da área de atuação que esse professor exerce.

\section{Desfechos dos tratamentos iniciados sem receita médica e efeitos adversos relacionados à prática da automedicação}

Dos entrevistados, a maioria afirmou ter melhorado completamente, como verifica-se na tabela 4. Segue um depoimento referente ao assunto:

\begin{abstract}
"A Automedicação ocorre porque nem sempre o atendimento médico é satisfatório e confiável, outras vezes demanda. No meu caso ocorre quando já conheço os sintomas e o resultado dos medicamentos. A escolha dos medicamentos ocorre baseada em receitas antigas ou experiência anterior bem sucedida (Margarida)".
\end{abstract}

Esses resultados corroboram para o aumento da aflição em relação à segurança dos pacientes, levando o praticante da automedicação ter a ideia de que sempre que se automedicar, os resultados serão positivos.

Dos efeitos adversos relatados, $78 \%$ afirmaram não apresentarem efeitos adversos após a prática da automedicação e $16 \%$ apresentou algum efeito adverso, contudo $5 \%$ não lembrou se passaram por esse tipo de reação e $1 \%$ não respondeu.

Dos pesquisados, Rosa, docente da área da saúde, mesmo sabendo dos perigos da automedicação relatou ter apresentado diversos episódios de espasmo muscular após a associação de um anti-histamínico e um analgésico.
Tabela 4 - Principais desfechos frente à prática da automedicação descritos pelos professores de nível superior do Campus Universitário de Sinop/MT, Brasil, 2013-2014

\begin{tabular}{l|c|c}
\hline \multicolumn{1}{c|}{ Variáveis } & N & \% \\
\hline Melhorou completamente (n: 82) & 64 & 78 \\
\hline Melhorou parcialmente (n: 82) & 24 & 29 \\
\hline Não melhorou (n: 82) & 2 & 3 \\
\hline $\begin{array}{l}\text { Procurou atendimento médico após se } \\
\text { automedicar-se (n: 82) }\end{array}$ & 10 & 12 \\
\hline $\begin{array}{l}\text { Utilizou outra medicação por conta } \\
\text { própria (n: 82) }\end{array}$ & 2 & 2,4 \\
\hline Conforme a bula (n: 82) & 3 & 4 \\
\hline Obteve melhora dos sintomas (n: 82) & 4 & 5 \\
\hline Sem controle (n: 82) & 1 & 1 \\
\hline Tiveram mais de um desfecho (n: 82) & 24 & 29 \\
\hline Apresentaram efeitos adversos (n: 82) & 13 & 16 \\
\hline Não apresentaram efeitos adversos (n: 82) & 64 & 78 \\
\hline Não responderam (n: 82) & 1 & 1 \\
\hline Não se lembram (n: 82) & 4 & 5 \\
\hline
\end{tabular}

Fonte: dados da pesquisa.

\section{DISCUSSÃO}

A proporção de indivíduos que praticam automedicação com idade de 31 a 60 anos é bem expressiva (84\%), semelhante ao estudo feito no município de São Paulo, no qual, aqueles com menos de 47 anos foram os que mais se automedicaram?

Diversos estudos indicam maior prevalência de automedicação na população feminina ${ }^{5-9-10}$. Isso pode ser explicado, pois as mulheres, devido as suas fases da vida: menarca, gestação e menopausa, estão mais suscetíveis à exposição de medicamentos, logo as campanhas educativas são mais direcionadas a elas e, assim, elas procuram com maior constância os serviços de saúde ${ }^{10-11}$.

Dos estudos encontrados sobre a automedicação, não há nenhum realizado no estado do Mato Grosso. Foi encontrado material referente ao tema realizado em outros estados, como São Paulo e Ceará ${ }^{9-12}$. Observa-se que a comunidade docente da UFMT-Campus Sinop é bastante diversificada considerando 0 aspecto naturalidade, podendo, talvez, influenciar na automedicação, quando falamos da cultura da automedicação poder ser mais forte em outros estados, já que são encontrados mais estudos em outros estados, referente ao tema, e essas pessoas podem influenciar a prática, trazendo os seus costumes de seu estado de origem.

Algumas pesquisas apontam que pessoas com nível superior tendem a se automedicar, principalmente por apresentarem maior conhecimento sobre medicamentos, melhor poder econômico, menor confiança nos médicos e maior autonomia sobre a própria saúde ${ }^{10}$. 
Quanto às pessoas com quem os docentes residem, podemos destacar residências com crianças, pois as crianças colaboram para o depósito de medicamentos no lar. Os medicamentos direcionados às crianças são fortemente compartilhados com outros moradores residentes, as sobras são reaproveitadas e normalmente não são armazenadas com as embalagens junto à bula, havendo uma pré-disposição à prática da automedicação, vencimento dos medicamentos e descartes incorreto ${ }^{13}$.

0 número de pessoas que vivem na mesma residência também pode ser um fator que contribui para a automedicação. Observa-se que quanto mais pessoas no mesmo habitat, maior a quantidade de medicamentos armazenados ${ }^{14}$.

Na pesquisa realizada no Rio Grande do Sul, a média de pessoas que moram na mesma residência, era de 4 a 5 pessoas por casa, sendo que a presença de medicamentos nos domicílios foi de $89,3 \%{ }^{15}$.

No que se refere às classes farmacológicas dos medicamentos mais utilizados pelos docentes, o estudo de Piotto et $a l^{15}$ corrobora ao resultado desta pesquisa, no qual $73,7 \%$ dos pesquisados se automedicaram também com o grupo dos Analgésico-Antitérmicos.

Os AINES também estiveram entre os mais utilizados, e apesar de parecerem inofensivos, fica o alerta de que esses medicamentos, ao mesmo tempo em que aliviam sintomas (dor, edema, dentre outros associados ao processo inflamatório), acarretando conforto e cura, também matam e, se utilizado de forma abusiva, aumentam o risco de intoxicações e interações medicamentosas ${ }^{11-16}$.

0 uso de antitussígeno e os antigripais foi semelhante ao estudo de Freitas e Zancanaro ${ }^{17}$, no qual das 95 pessoas entrevistadas, 45 afirmaram fazer uso de medicamentos antigripais e 32 utilizaram antitussígeno.

Ainda neste contexto, deve-se ter cautela com esses medicamentos, pois muitos deles aparecem no mercado farmacêutico nacional, conhecidos por ter eficácia duvidosa e pela presença de muitos produtos desnecessários, sendo muito divulgados, mas com pouca orientação para o público gera ${ }^{16}$.

A escolha dos anti-histamínicos assemelhou-se ao estudo realizado por Andrade et $a l^{16}$, em que $26 \%$ dos pesquisados referiram fazer uso desses fármacos.

O uso de antibióticos, embora devesse ser feito somente mediante a receita médica, são vendidos livremente. 0 uso incorreto vem contribuindo para o aumento da resistência bacteriana, se tornando um problema de saúde pública ${ }^{11}$.

No contexto das drogas psicoativas, quando usadas descontroladamente, causam dependência farmacológica e, muitas vezes, os indivíduos usuários mesmo estando em situações favoráveis, passam a utilizar a droga para combater a monotonia do cotidiano, ansiedade, depressão, dor ou para obter prazer².

Das patologias elencadas, várias outras pesquisas apresentam em destaque a cefaleia, que vem liderando o ranking das causas pelas quais a população se automedica ${ }^{11-16-17}$.

Ao falar dos resfriados/gripe, faz-se necessária atenção, pois são doenças autolimitadas e, por este motivo, seu tratamento, que normalmente é feito sem prescrição médica, não deve passar dos sete dias, o período natural de evolução da doenç ${ }^{16}$. 0 enfermo procura sempre uma solução imediata para o seu problema e por isso a cefaleia e os resfriados são alvos da automedicação ${ }^{18}$.

Quanto à febre, que ficou em terceiro lugar na seleção dos docentes, na pesquisa realizada por Oliveira e Pereira ${ }^{18}$ é um dos sintomas mais favoráveis à prática da automedicação.

De acordo com um estudo realizado em Tocantins, com os profissionais de uma drogaria privada, foi analisada a porcentagem de atendentes desta drogaria que indicariam, conforme a gravidade do sintoma apresentado, o paciente a procurar o médico. A dor muscular foi um dos sintomas menos indicados por eles à procura pelo médico, apenas $3,77 \%$ recomendaram a busca, já que as dores musculares podem ser tratadas com analgésicos e antiinflamatórios, considerando que a evolução das dores são benignas e que o tratamento é apenas paliativo ${ }^{19}$.

As alergias, sinusite e ansiedade foram as patologias menos citadas pelos professores, semelhante ao levantamento realizado por Freitas e Zancanaro ${ }^{17}$, onde a minoria optou por essas variáveis.

Os sinais e sintomas são fatores importantes para mensurar a evolução e a gravidade de uma doença, porém, o indivíduo se automedica para alívio imediato e, por fim, pode estar mascarando uma doença grave que pode se tornar um problema mais sério ou com sequelas até mesmo irreversíveis.

A respeito das características motivacionais para adesão à prática da automedicação, o presente estudo apresenta que a maior porcentagem foi de docentes que automedicaram a si mesmos, sem interferências externas. Em uma pesquisa com universitários, divididos em 4 áreas: gestão e jurídica, tecnológica, saúde e comunicação e educação, o conhecimento próprio a respeito do problema de saúde e do medicamento influenciou significativamente a automedicação por parte dos universitários da área da saúde, no entanto, não houve diferença na prática relacionada à área de formação. É uma observação importante, já que, a partir daí, pode-se planejar uma estratégia de promoção do uso racional de medicamentos direcionado a um público específico ${ }^{20}$.

Já aqueles indivíduos influenciados por familiares ou por prescrições antigas, eram os que faziam uso das sobras de medicamentos já guardados nas residências proveniente de tratamentos anteriores ${ }^{20}$.

A pequena busca pelo farmacêutico nesse estudo, é controverso ao de Silva et $a l^{5}$,em que $80,24 \%$ dos indivíduos optaram pelo farmacêutico na hora de se automedicar. 
Sabe-se que nem sempre é o farmacêutico que está disponível para atendimento ao público nas farmácias, dessa forma, os balconistas acabam assumindo o papel dos mesmos, se tornando na maioria das vezes prescritores, favorecendo o uso inadequado dos medicamentos e contribuindo igualmente para que a população use a farmácia como substituto dos serviços de saúde e do médico ${ }^{16}$.

Desta forma, pode-se perceber a importância do farmacêutico na atenção primária, ou seja, quando é necessária alguma informação sobre algum medicamento, para que, assim, possa diminuir os riscos associados a problemas de medicamentos e também na automedicação, ajudando no bem estar social e nos níveis de saúde geral ${ }^{18}$.

Uma grande preocupação é a venda influenciada por meios de comunicação. A internet, por disponibilizar informações referentes à bula, posologia e até a facilidade de compra de medicamentos sem receita, favorece o início de um tratamento, sem consulta médica prévia ${ }^{18}$.

Os conhecimentos adquiridos na universidade podem influenciar na realização da prática, o que tendencia a realização da automedicação, principalmente entre aqueles professores da área da saúde, não excluindo as outras áreas, já que indivíduos com nível superior tendem a se automedicar com maior frequência ${ }^{5}$.

No estudo realizado com adolescentes, $17 \%$ deles afirmaram que utilizaram medicamentos sem receita médica, pois, segundo eles, já tinham experiência prévia com o medicamento ${ }^{12}$. Mais expressivo foi o resultado encontrado em uma universidade do Sul de Minas Gereis entre os acadêmicos da área da saúde, em que a maioria dos estudantes solicitou conselho com terceiros para prática da automedicação 5 .

A pesquisa apontou que grande parte dos docentes seguiram as instruções da bula, ao automedicarem-se. Esse resultado pode ser observado também no estudo de Silva et $a l^{5}$, onde a maioria dos pesquisados adotam as instruções da bula como fonte de informação para se automedicar.

O profissional farmacêutico se destaca como um dos maiores aconselhadores, sendo necessários mais estudos para saber as condições a despeito do responsável no momento em que um paciente busca solicitações na farmácia ${ }^{16}$

É importante ressaltar que o farmacêutico depois de analisar a situação do cliente deve intervir adequadamente incluindo, se necessário, a procurar outro profissional de saúde mais indicado, terapias não-farmacológicas e farmacológicas quando se trata de medicamentos que não precisam de prescrição $0^{13}$.

A pesquisa mostrou o relevante uso de receitas antigas, fato que requer cautela, pois nem sempre os sintomas parecidos carecem da mesma terapia medicamentosa ${ }^{13}$.

Referente ao desfecho positivo da automedicação descrita pelos docentes, de maneira semelhante, no estudo de Oliveira e Pereira ${ }^{18}$, a maioria relatou que obteve resultados esperados ao se automedicar, ou seja, melhoraram completamente.

A automedicação passa ser uma forma rápida de alívio dos sintomas e, muitas vezes, a cura de certas doenças, entretanto, mesmo os medicamentos prescritos por médicos em doses não recomendadas podem levar a prejuízos irreversíveis ${ }^{18}$.

Alguns docentes afirmaram terem apresentado efeitos adversos. Neste sentido, segurança de que o fármaco lembra a "saúde" leva os indivíduos a automedicarem-se, não percebendo os riscos de tal prática, porém vale ressaltar que nenhuma substancia farmacológica é inofensiva ao organismo, ocorrendo sempre contraindicações e reações adversas, seja o fármaco utilizado de forma adequada ou negligente ${ }^{12}$.

Muitos medicamentos que não exigem receita médica, contêm formulações com mais de um princípio ativo, que na maioria das vezes são ignoradas, levando ao uso simultâneo a outras substâncias já prescritas. Nesta mesma, houve perceptível dificuldade por parte dos pesquisados em responder a quantidade de princípios ativos contidos nas medicações utilizadas ${ }^{16}$

\section{CONCLUSÃO}

Fica evidente neste estudo que todos os pesquisados têm o hábito da automedicação. São, principalmente, professores entre 31 e 60 anos, sexo feminino, casados, que moram com companheiros e filhos, naturais de outro estado e que são somente graduados. A partir disto, é possível traçar um perfil de pessoas que se automedicam e conhecer as razões pelas quais as pessoas o fazem e, dessa forma, planejar estratégias mais específicas.

Dentre as limitações encontradas, estiveram a recusa de alguns docentes em participarem do estudo, não sendo possível alcançar todos os professores da universidade, e a dificuldade de alguns docentes em responder o questionário, devido não lembrar com exatidão os medicamentos utilizados no momento em que se automedicou.

A partir dos achados encontrados, faz-se necessário realizar novos estudos sobre o assunto, envolvendo um maior número de docentes, visto que é uma prática comum entre os mesmos.

É importante que a comunidade docente, principalmente da área da saúde, por ser detentora de conhecimento privilegiado e ser formadora de opiniões, seja conscientizada e multiplique as informações, quanto ao uso responsável de medicamentos, já que influenciam a população direta ou indiretamente sobre hábitos de vida saudáveis.

Isso não exclui a necessidade de traçar estratégias para conscientizar os professores de outras áreas, incentivando-os a buscar o profissional correto quando necessitarem de algum serviço de saúde, sendo esse profissional médico ou não. 


\section{REFERÊNCIAS}

1. Vitor RS, Lopes CP, Menezes HS, Kerkhoff CE. Padrão de consumo de medicamentos sem prescrição médica na cidade de Porto Alegre, RS. Cienc Saude Colet [Internet]. 2008 [acesso em 29 ago 2016]; 13(Supl.0):737-43. Disponível em: http://www.scielo.br/scielo.php?script=sci_ arttext \&pid=S1413-81232008000700024

2. Baggio MA, Formaggio FM. Automedicação: desvelando o descuidado de si dos profissionais de enfermagem. Rev enferm UERJ [Internet]. 2009 [acesso em 29 ago 2016]; 17(2):224-28. Disponível em: http://www.facenf.uerj.br/v17n2/v17n2a15.pdf.

3. Arrais PSD, Coelho HLL, Batista MCDS, Carvalho ML, Righi RE, Arnau JM. Perfil da automedicação no Brasil. Rev Saude Publica [Internet]. 1997 [acesso em 29 ago 2016]; 31(1):71-77. Disponível em: http://www.scielo.br/scielo.php?pid=S0034$89101997000100010 \&$ script=sci_abstract \&tlng=pt.

4. Automedicação [editorial]. Rev Assoc Med Bras [Internet]. 2001 [acesso em 29 ago 2016]; 47(4): 269-70. Disponível em: http://www.scielo.br/pdf/ramb/v47n4/7366.pdf.

5. Silva LSF, Costa AMDD, Terra FS, Zanetti HHV, Costa RD, Costa MD. Automedicação em acadêmicos do curso de graduação da área da saúde de uma universidade privada do Sul do Estado de Minas Gerais. Odontol Clin Cient [Internet]. 2011 [acesso em 30 ago 2016]; 10(1):57-63. Disponível em: http://revodonto.bvsalud.org/scielo.php?pid=S167738882011000100011 \&script=sci_arttext.

6. Bastos JLD, Duquia RP. Um dos delineamentos mais empregados em epidemiologia: estudo transversal. Scientia Medica [Internet]. 2007 [acesso em 24 mar 2017]; 17(4):22932. Disponível em: http://revistaseletronicas.pucrs.br/ojs/ index.php/scientiamedica/article/download/2806/2634.

7. Carmo H, Ferreira MM. Metodologia da investigação. Guia para Auto-Aprendizagem. 2a. ed. Portugal: Universidade Aberta; 2008.

8. Minayo MCSO. O desafio do conhecimento: pesquisa qualitativa em saúde. 12a. ed. São Paulo: Hucitec; 2010.

9. Schmid B, Bernal R, Silva NN. Automedicação em adultos de baixa renda no município de São Paulo. Rev Saude Publica [Internet]. 2010 [acesso em 30 ago 2016]; 44(6):1039-45. Disponível em: http://www.scielo.br/scielo.php?script=sci_ arttext \& pid=S0034-89102010000600008.

10. Barros ARR, Griep RH, Rotenberg L. Automedicação entre os trabalhadores de enfermagem de hospitais públicos. Rev Lat Am Enfermagem [Internet]. 2009 [acesso em 28 ago 2016]; 17(6): 1015-22. Disponível em: http://www.scielo.br/pdf/rlae/ v17n6/pt_14.pdf.

11. Aquino DS, Barros JAC, Silva MDP. A automedicação e os acadêmicos da área de saúde. Cienc Saude Colet [Internet]. 2010 [acesso em 30 ago 2016]; 15(5):2533-38. Disponível em: http://www.scielo.br/scielo.php?pid=S141381232010000500027 \&script=sci_abstract\&tlng=pt.

12. Silva MI, Catrib AMF, Matos VC, Gondim APS. Automedicação na adolescência: um desafio para a educação em saúde. Cienc Saude Colet [Internet]. 2011[acesso em 29 ago 2016]; 16(Supl. 1):1651-60. Disponível em: http://www. scielosp.org/scielo.php?script=sci_arttext \&pid=S141381232011000700101\&lng=pt.

13. Beckhauser GC, Souza JM, Valgas C, Piovezan AP, Gatalo D. Utilização de medicamentos na pediatria: a prática de automedicação em crianças por seus responsáveis. Rev Paul Pediatr [Internet]. 2010 [acesso em 30 ago 2016]; 28(3):26268. Disponível em: http://www.scielo.br/scielo.php?script=sci_ arttext \&pid=S0103-05822010000300002.

14. Figueiredo MC, Silva KVCL, Bonacina CM, Ortiz FT. Armazenagem de medicamentos em domicílios pelos moradores do bairro Figueirinha, em Xangri-lá, RS. Rev Ci med biol. 2011; 10(2):140-45.

15. Piotto FRSB, Nogueira RM, Pires OC, Pelógia NCC, Posso IP. Prevalência da dor e do uso de analgésicos e anti-inflamatórios na automedicação de pacientes atendidos no Pronto-Socorro Municipal de Taubaté. Rev Dor [Internet]. 2009 [acesso em 30 ago 2016]; 10(4):313-17. Disponível em: http://bvsms.saude. gov.br/bvs/publicacoes/publicacao_artigo_pesquisa_unesp_ cerestpp.pdf.

16. Andrade MA, Silva MVS, Freitas O. Assistência farmacêutica como estratégia para o uso racional de medicamentos em idosos. Semina Cienc Biol Saude [Internet]. 2004 [acesso em 28 ago 2016]; 25(1):55-63. Disponível em: http://www.uel.br/ revistas/uel/index.php/seminabio/article/view/3626/2930.

17. Freitas K, Zancanaro V. Prevalência de automedicação na população do município de Faiburgo -SC. Caçador [Internet]. 2012 [acesso em 29 ago 2016]; 1(1):38-58. Disponível em: http://www.periodicosuniarp.com.br/ries/article/view/3.

18. Oliveira FCS, Pereira LFS. Incidência de automedicação na população de Trindade e região. In: Artigo apresentado no III Seminário de Pesquisas e TCC da FUG. Goiás; 2012. p. 95-103.

19. Mazutti AR, Teixeira LAJ, Gontijo EEL, Silva MG. Fatores associados à automedicação: Uma análise a partir dos profissionais de drogarias privadas de Gurupi, Tocantins. Rev Movimenta [Internet]. 2013 [acesso em 30 ago 2016]; 6(1):398-410. Disponível em: http://www.nee.ueg.br/seer/ index.php/movimenta/article/viewFile/649/494.

20. Galato D, Madalena J, Pereira GB. Automedicação em estudantes universitários: a influência da área de formação. Cienc Saude Colet [Internet]. 2012 [acesso em 30 ago 2016]; 17(12):3323-30. Disponível em: http://www.scielo.br/pdf/csc/ v17n12/17.pdf. 